\title{
Integrated development of digital agribusiness platform to support import substitution of food products
}

\author{
Elmira Amirova ${ }^{1, *}$, Maxim Kuznetsov ${ }^{1}$, Elena Khakimova $^{2}$ and Aurelia Tolmacheva ${ }^{2}$ \\ ${ }^{1}$ Kazan State Agrarian University, Kazan, 420015, Russia \\ ${ }^{2}$ Kazan National Research Technological University, Kazan, 420015, Russia
}

\begin{abstract}
The paper outlines a framework for the deployment of a digital agrarian platform as an element constituting a unified economic system to promote digital development of Russia. The study aims to identify ways of integrated development of digital platform to increase the economic efficiency of agricultural producers and ensure the import substitution of food products in the country. The paper provides a rationale for digital transformation of agricultural production, integrated digital platform for the agrarian economy of Russia, digitalization processes both at the level of constituent entities of the Russian Federation and the country at large.
\end{abstract}

\section{Introduction}

The era of digital globalization is shaped by data flows that contain ideas and innovations. Technologies, such as the Internet of Things, combining many smart devices that are gradually becoming smaller in size, deliver solid performance. They will be crucial for responding to agricultural challenges that involve low economic efficiency, especially when compared with the level of development of this kind of enterprises in highly developed countries of the world.

The production of even the simplest agricultural products is based on a wide range of scientific and technical knowledge. The achievements of scientific and technological progress that marked the late 20th and early 21st centuries, changed our world beyond recognition, opening up completely new, unprecedented sales markets and creating new needs for each of us. Computers, smartphones, uninterrupted access to the Internet have approved a new economic reality, having spread throughout the world in just a couple of decades. Today is the time when smart digital solutions should help the agrarian industry cope with the challenges of increasing labor productivity and sustainable development $[1,16]$.

The National Digital Agriculture Platform that, besides aggregating and highlighting information and the best innovative models of the industry, provides convenient data access services and integrates with platforms of related industries. It will provide a significant synergistic effect from the use of digital technologies. The Platform should become the basis for building an ecosystem of digital services and services for agriculture at the Russian Ministry of Agriculture.

The implementation of project initiatives to accelerate agricultural sectors of the country, giving impetus to the development of partnerships between the state and private owners is an important goal for import substitution of food products and building up the export potential of the Russian agricultural sector.

In modern business conditions, there is a need to introduce a large list of various digital technologies into the Russian agricultural economy. These include integrated farm management systems, robotic systems, unmanned agricultural machinery systems and other specific technologies.

Agriculture is one of the most promising sectors for the introduction of digital technologies. This is proved by the Western experience of using "smart technologies" in the agricultural sector.

Moreover, in Russia, a demand for digitalization of the agricultural sector is just about to start shaping. To ensure that they have maximum effect, it is necessary to deploy integrated platform solutions rather than single systems. This will give a synergistic effect and will increase agricultural efficiency [2, 5, 18].

\section{Literature review and examples}

New information, bio- and nanotechnologies, significant changes in the value chain, altering consumer preferences and attitudes, climate change, the need for digitalization and the creation of digital agribusiness platforms - this is not a full list of factors that will affect the agricultural sector in Russia and in world in the near future [3].

The literature presents various definitions of the term "digital platform". They include the following $[4,6,8$, 15]: "A key tool for digital transformation of conventional industries and markets that distinguishes between digitalization (digital automation) and digital transformation strategies"; "A group of technologies that

*Corresponding author: elmira_amirova@mail.ru 
are used as the basis for the creation of a specific and specialized system of digital interaction"; "A high-tech business model that creates value by facilitating exchanges between two or more interdependent groups of participants"; "An enterprise that provides mutually beneficial interactions between third-party producers and consumers".

A digital platform is most often defined as "a system of mutually beneficial algorithmic relationships among a significant number of independent participants in an economic sector (or field of activity) performed in a shared information environment, leading to lower transaction costs through the use of a digital data processing package and changes in the division of labor" [7].

Among all digital platforms (instrumental, infrastructural and applied), the platform of agriculture and agricultural sector as such can be attributed to the applied digital platform, that is primarily targeted at the final consumer on the market.

The Russian agricultural sector visually represents a section of those socio-economic and scientifictechnological processes that embrace all sectors of Russian economy. It combines some technologies that were invented in different periods of time, sometimes with a hundred-of-year span [4].

Modernized with the latest technology, transnational holdings coexist with numerous farms. Staff shortages and decades-long competency profiles are compensated through related sectors and areas of expertise. What is more, mainly low-value products are exported, while losses to logistics and operating costs are still enormous $[6,19,20]$.

Meanwhile, it is the agricultural sector that claims to be the key demonstration platform for the outputs of the new technological revolution: robotic "industry 4.0" technologies transfer nearly all agricultural machinery to an unmanned mode.

The Internet of Things and the "Internet of Everything" unite the entire production chain into a single ecosystem - from the creation of new fertilizers and species of animals and plants to the release of functional products that can radically enhance human properties. The concept of a smart city expands opportunities for vertical farming. New space and biotechnological research demonstrate space exploration outside the Earth [17].

The way out of difficult economic situation in the agricultural sector is possible by introducing technological innovations, otherwise known as digital platforms. An example of such a platform is the activities of IBM Research and Agri-tech startup Hello Tractor that developed an artificial intelligence and blockchain platform for African farmers. They created a "digital wallet" suited to support businesses in connecting small farmers to equipment and data analysis in an attempt to increase productivity $[9,14,21]$.

The online platform available to Hello Tractor customers will employ digital ledger and machine learning to collect, track and share data, concurrently "creating end-to-end trust and transparency in the agribusiness value chain," the IBM release said.
The digital wallet will rely on remote and IoT-based weather and artificial intelligence methods to help farmers determine crops and resources, choose the time to plant, improve and predict yield [10].

\section{Methodology}

The methodology is composed of scientific analysis, including logical and comparative analysis, and generalization of acquired knowledge. The methodology is based on a combination of a statistical and expert approach to obtain final estimates of each subject of the Russian Federation, regardless of its size, population and geographical location [12]. A digital penetration rate in the agricultural sectors of the constituent entities of the Russian Federation is evaluated using statistical and qualimetric methods.

\section{Strategy}

The digital transformation of agricultural production requires the following activities:

1. Implement methodological, informational and technical solutions for the development of digital agribusiness platforms, including an extremely urgent issue of import substitution. With this in view, it is necessary to create a pilot zone for the development of software, hardware and information solutions involving industry enterprises.

2. Continue the improvement of a legal framework to encompass organizational regulations and interaction procedures within the functioning of digital agribusiness platforms.

3. Ensure the development of unified standards and interfaces for the integration of digital agribusiness platforms with state and departmental information systems FSSS, agribusiness.

4. Engage federal and regional executive authorities of the Russian Federation, responsible for the creation of digital agribusiness platforms, to intensify the work on the creation and development of digital platforms for the period up to 2030.

5. Ensure the protection of intellectual property created in the framework of ongoing research and development.

6. Approve proposals for improving digital agribusiness platforms, facilitate the appropriate scientific and methodological support, and the development of prototypes of the information platform based on domestic software with the organization of pilot projects at the local and regional levels.

The key elements of the development strategy for the digital agribusiness platform are:

1. Digital base for decision support systems in the agricultural sector (digitization of maps, databases accessible via API, etc.).

2. Analytics and big data - analytical platforms for the entire agricultural sector (forecasting yield, climate risks, etc.).

3. Digitalization of production - "Smart" technology and robotics (agricultural equipment with $\mathrm{AI}$ and 
analytics, satellites and drones, irrigation systems and greenhouses).

4. Digitalization of sales - product traceability from "farmer to the table" based on blockchain, electronic exchanges for the sale of agricultural products [13].

Through "digitization" of the agricultural process, in whole or in part, the agricultural sector can be conceived as a big computer game in which users can choose their role (farmer, biotechnologist, investor or state representative) and see the results of the actions taken $[13,15]$.

\section{Results}

The agricultural sector is a combination of technological and economic structural elements that are interconnected. In Russia, there are some pilot regions to create a system of end-to-end scientific and industrial cooperation.

The digitalization of the agricultural sector will be able to provide the required breakthrough in the application of intensive technologies, selection, reclamation, fertility support and scientific and industrial cooperation. In the future, it is envisaged to construct logistics centers, "smart farms", to lay gardens, etc. Boosting agribusiness in crop production and animal husbandry, developing mechanisms and measures of state support to stimulate the introduction of digital technologies, and organizing trade are all possible by creating a digital agricultural platform (Fig. 1). The above is required to increase the economic efficiency of agricultural production for import substitution and export of agricultural products.

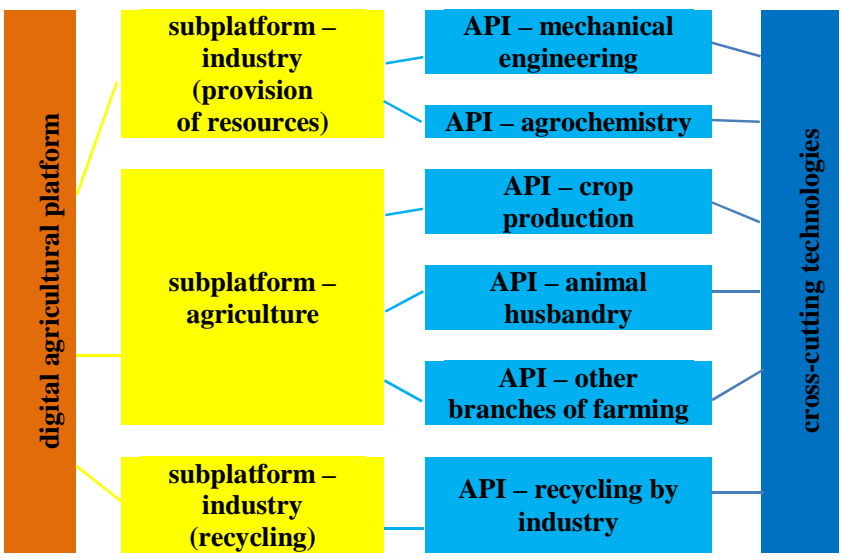

Fig. 1. Digital Agricultural Platform

The digital penetration rate can be evaluated using an integral criterion: $\mathrm{K} 0(\mathrm{t})=\mathrm{a} \times \mathrm{Knr}(\mathrm{t})+\mathrm{b} \times \mathrm{Kpe}(\mathrm{t})+\mathrm{c} \times$ $\operatorname{Krctg}(\mathrm{t})+\mathrm{d} \times \operatorname{Kii}(\mathrm{t})+\mathrm{e} \times \mathrm{Kis}(\mathrm{t})+\mathrm{f} \times \mathrm{Kfee}(\mathrm{t})+\mathrm{j} \times$ Kse, where $\mathrm{K} 0$ (t) is the final value of the digital penetration rate. It reflects the effectiveness of public coverage in open sources of digitalization, including the implementation of the Digital Agriculture Program in the subject of the Russian Federation and main digitalization solutions in the agricultural economy to create the conditions for digital transformation of all sectors of rural economy and social infrastructure based on the analysis of information from open sources at time t. K ( $t$ ) is public coverage of economy digitalization in the subject of the Russian Federation at time t; a, b, c, d, e, f, $\mathrm{j}$ are weighting factors for assessing the level of public coverage in open sources of digitalization development: "normative regulation", "personnel and education", "research competencies and technological groundwork", "information infrastructure" and "information security", "financial and economic efficiency", "social efficiency", respectively.

They are determined by factor analysis and expert evaluations, and satisfy the standardization condition. Thus, the digital penetration rate allows for an expert assessment in the context of each subject of the Russian Federation, the accuracy and reliability of which corresponds to the accuracy and reliability of information obtained from open sources.

\section{Examples}

The Digital Agro Company responsible for IT platforms for farmers has acquired a $25 \%$ stake in Infobis that specializes in the development of the Agrosignal planning, online control and management system for the agricultural business. This will be followed by a multiple increase in digitalization in the Russian market. The Ministry of Agriculture predicts that by 2026, the domestic market for digital technologies that contribute to the development of agriculture will increase by 5 times.

At present, its volume does not exceed 360 billion rubles. In Russia, digital agriculture is now developing in five basic dimensions outlined by the Ministry of Agriculture: effective hectare, smart contracts, "Field to Port" agro-export, agro-solutions for agribusiness and the "Land of Knowledge". Regulations form the basis for efficient production in any business.

AgroStream LLP has developed templates for regulations for a sound, effective digital agricultural enterprise. The regulations take into account all critical requirements for the implementation of production technology, planning, organization and control. All templates are time-tested and improved in real enterprises, varying in size, organization of labor, crop rotation, and the use of technology. The provision of agricultural enterprise regulations is part of the unique AgroStream IP implementation methodology.

\section{Conclusion}

The deployment of digital agribusiness platforms will: reduce risks, monitor climate change, increase crop yields and animal productivity. It will be possible to timely plan all field work, reduce production costs based on efficient use of resources and science-based approaches, reduce transaction costs for buying and selling, simplify the supply chain of products from the field to the consumer, reduce the shortage of skilled labor, provide rural producers with timely critical information, etc.

By 2026, the domestic market for digital technologies that contribute to the development of 
agriculture will increase by 5 times. At present, its volume does not exceed 360 billion rubles.

In Russia, digital agriculture is now developing in five basic areas outlined by the Ministry of Agriculture: effective hectare, smart contracts, "Field to Port" agroexport, agro-solutions for agribusiness, and the "Land of Knowledge". In some regions of our country, they intend to launch the first stages of digital platforms in the agricultural sector.

\section{References}

1. K. Yusupov, K. Grishin, V. Timiryanova, D. Krasnoselskaya, Spatial patterns of profitable firms' location: empirical evidence from Russia, Amazonia Investiga 8(24), 452-463 (2019)

2. F. Nezhmetdinova et al., Global challenges for agrarian sector of Russian economy and its human resources, Revista Espacios 39(26) (2018) ISSN 07981015

3. A.T. Iskhakov, G.S. Klichova, The use of solar batteries in agriculture and accounting of generated electricity, Mediterranean J. of Soc. Sci. 5(12), 187191 (2014)

4. E.F. Amirova, L.I. Petrova, E.V. Ziuzya, V.V. Sleptsov, T.I. Krishtaleva, M.V. Kuznetsova, Import substitution as an economic incentive mechanism for Russian commodity producers, Int. J. of Civil Engineer. and Technol. 10(2), 926-931 (2019)

5. O.V. Kirillova, Factors determining food security of the country, in: Coll. Sustainable Development of Agriculture in the Context of Global Risks Proc. of the Sci. and Pract. Conf. World Trade Organizat. pp. 403-407 (2016)

6. E.Yu. Ermakova, Yu.F. Korotkov, M.G. Kuznetsov, N.A. Nikolaev, Cleaning contaminated water by gravity flotation, Chem. and Petrol. Engineer. 46(12), 40-44 (May 2010)

7. N.F. Kashapov, M.M. Nafikov, M.X. Gazetdinov, M.M. Nafikova, A.R. Nigmatzyanov, Innovative production technology ethanol from sweet sorghum, IOP Conf. Ser. Mater. Sci. and Engineer. 134 012012 (2016)

8. T. Khudyakova, A. Shmidt, S. Shmidt, Implementation of controlling technologies as a method to increase sustainability of the enterprise activities, Entrepreneurship and Sustainability Issues 7(2), 1185-1196 (2019)

9. I.N. Safiullin, L.G. Ibragimov, E.F. Amirova, N.V. Karpova, State regulation of the agricultural sector in the context of sanctions and the development of the digital economy, Bull. of Kazan State Agrar. Univer. 14(3(54)), 133-137 (2019)
10. T.A. Khudyakova, A.V. Shmidt, Methodical approaches to managing the sustainability of enterprises in a variable economy, Espacios, 39(13), 28 (2018)

11. D.Kh. Krasnoselskaya, D.R. Khamzina, S.M. Goloviznin et al., Determination of capital accumulation in region using benchmarking tool, Espacios 40(35) (2019)

12. O. Rostova, S. Shirokova, N. Sokolitsyna, Management of project for automation of investment control at industrial enterprise, IOP Conf. Ser. Mater. Sci. and Engineer. 497(1), 012017 (2019)

13. M. Zharova, S. Shirokova, O. Rostova, Management of pilot IT projects in the preparation of energy resources, E3S Web of Conf. 110, 02033 (2019)

14. D.V. Bunkovsky, Entrepreneurial risk management tools, Manag. Issues 1(37), 65-76 (2019)

15. E.F. Amirova, O.Y. Voronkova, K.A. Pyurveeva et al., Functioning of agroindustrial complex in the conditions of digital economy, Int. J. of Mechan. Engineer. and Technol. 9(12), 586-594 (2018)

16. N.V. Zhakhov, V.S. Krivoshlykov, N.A. Slavova et al., State Influence on the Development of Digital Economy of Rational Nature Use in Agricultural Sector of the Region's Economy, in: Proc. of XVIII Int. Sci. and Pract. Conf. Modern Trends in Agricultural Production in the World Economy, pp. 182-189 (2020)

17. D.V. Bunkovsky, Methods for minimizing enterprise risks, Manag. Issues 5(35), 125-129 (2018)

18. F.F. Gatina, A.R. Artamonycheva, Features and criteria for attracting investment in the Russian economy, Bull. of Kazan State Agrar. Univer. 3(2(8)), 13-15 (2008)

19. A.T. Iskhakov, The development of cheese making to increase the economic activity of dairy enterprises of the Republic of Tatarstan, in: Proc. of the Int. Sci.-Pract. Conf. Dedicated to the 100th Anniversary of Agricult. Science, Education and Enlightenment in the Middle Volga Region: Agriculture and Food Security: Technology, Innovation, Markets, Personnel, pp. 690-694 (2019)

20. O.V. Kirillova, On the features of foreign trade in agricultural products of the Russian Federation, in: WTO coll. Sustainable Development of Agriculture in the Context of Global Risks Proc. of the Sci. and Pract. Conf., pp. 398-402 (2016)

21. I. Sokolova, O. Leskina, O. Orlovtseva, E. Gubanova, T. Kanikhin, Application of artificial intelligence capabilities for practical needs of participants in economic processes, in: Proc. of the 33th Int. Busin. Inform. Manag. Associat. Conf., IBIMA 2019: Education Excellence and Innovation Management through Vision 2020, pp. 8592-8602 (2019) 